Published in final edited form as:

Lung Cancer. 2020 January ; 139: 68-72. doi:10.1016/j.lungcan.2019.11.001.

\title{
Decreasing use of epidural analgesia with increasing minimally invasive lobectomy: Impact on postoperative morbidity
}

\author{
Masha Zeltsman ${ }^{1}$, Jordan Dozier ${ }^{1}$, Raj G. Vaghjiani ${ }^{1}$, Alexandra Poch ${ }^{1}$, Takashi Eguchi ${ }^{1}$, \\ Alessia Pedoto $^{2}$, David R Jones ${ }^{1}$, Prasad S. Adusumilli ${ }^{1,3}$ \\ ${ }^{1}$ Thoracic Service, Department of Surgery, Memorial Sloan Kettering Cancer Center, 1275 York \\ Ave, New York, NY, USA \\ ${ }^{2}$ Department of Anesthesiology and Critical Care Medicine, Memorial Sloan Kettering Cancer \\ Center, 1275 York Ave, New York, NY, USA \\ ${ }^{3}$ Center for Cell Engineering, Memorial Sloan Kettering Cancer Center, 1275 York Ave, New York, \\ NY, USA
}

\begin{abstract}
Objective: The goal of this study is to investigate the use of EA and its impact on the postoperative short-term outcomes of patients with non-small cell lung cancer (NSCLC) who received a lobectomy by either minimally invasive surgery (MIS) or thoracotomy.

Materials and Methods: We investigated 793 patients who underwent lobectomy for pathological stage I-III NSCLC without induction therapy during two time periods, an early-time period (2009-2010: MIS, n=204 [53\%]; and thoracotomy, $\mathrm{n}=182$ [47\%]) and a late-period (2014-2015: MIS, n=308 [76\%]; and thoracotomy, n=99 [24\%]). Patient characteristics, including pulmonary function tests, comorbidities, and use of EA, as well as short-term outcomes, including length of stay, morbidity, and mortality were assessed and compared between early-and late-time periods. We also compared patients who received EA $(n=150)$ with patients who did not receive EA ( $\mathrm{n}=158)$ following MIS lobectomy in the late-time period.
\end{abstract}

Results: The use of MIS lobectomy increased during the late-time period compared to the earlytime period ( $\mathrm{p}<0.001)$. In patients who underwent MIS lobectomy, the use of EA significantly decreased in the late-time period compared to the early-time period (2009-2010 vs. 2014-2015, $95 \%$ vs. $51 \% ; \mathrm{p}<0.001)$. There was no difference in postoperative morbidity and mortality between the two time periods in both MIS and thoracotomy. In the late-time period MIS group, the length of stay in the no EA group $(n=150)$ was shorter than that in the EA group $(n=158)$ (3 vs. 4 days, $\mathrm{p}=0.038$ ). There was no difference in morbidity and mortality between the EA and no EA groups.

Conclusion: In our study cohort, the observed decrease in the use of EA with the increasing rate of MIS lobectomy did not negatively affect postoperative short-term outcomes.

Corresponding author: Prasad S. Adusumilli, MD, FACS, FCCP, Deputy Chief and Attending, Thoracic Service, Department of Surgery, Vice Chair for Translational Research, Department of Surgery, Director, Mesothelioma Program, Head, Solid Tumors Cell Therapy, Cellular Therapeutics Center, Memorial Sloan Kettering Cancer Center, 1275 York Avenue, New York, NY 10065, Phone: (212) 639-8093; Fax: (646) 422-2340, adusumip@ mskcc.org. 


\section{Keywords}

postoperative analgesia; video-assisted thoracoscopic surgery; lobectomy; non-small cell lung cancer

\section{Introduction}

The last decade has seen a transition in the surgical approach to lobectomy, from thoracotomy to minimally invasive surgery (MIS), for treating patients with early-stage nonsmall cell lung cancer (NSCLC) [1]. Growing evidence has demonstrated that MIS lobectomy, including video-assisted thoracic surgery (VATS) and robotic-assisted thoracic surgery (RATS), is associated with fewer postoperative complications such as arrhythmias and pneumonia and shorter chest tube duration and length of hospital stay [2-8]. Recently, several national database studies reported the outcomes of propensity-matched patients who underwent MIS versus open thoracotomy. These studies suggested that MIS has better outcomes than thoracotomy in regard to complication rate [9-15] and hospital stay [10, 12$14,16]$, while demonstrating equivalent long-term survival $[13,16,17]$.

Regarding postoperative pain, although the prevalence of chronic symptoms following MIS has remained comparable to that of thoracotomy, investigators have noted decreased pain during the acute postoperative period following MIS [5, 18]. Bendixen et al. recently conducted a prospective randomized study and reported that VATS was associated with less postoperative pain and better quality of life during the first 12 months following surgery, compared to anterolateral thoracotomy [19]. In addition, a recently published study demonstrated that postoperative pain intensity was less in patients following RATS compared to open thoracotomy [20]. However, there is limited data available on the effect of this improved pain control on patient morbidity and mortality.

Postoperative pulmonary complications occur in $19-59 \%$ of patients undergoing thoracic surgery [21]. It is crucial to optimize perioperative analgesia in order to mitigate the compromising effects of pain on postoperative respiratory function and patient morbidity [22]. As such, EA has traditionally been considered the standard for patients undergoing major open abdominal and open thoracotomy surgeries [23, 24]. Early meta-analysis of trials assessing the effect of EA on patient outcomes following a variety of open operations, revealed that EA decreases the incidence of pulmonary complications (e.g., atelectasis, infection, etc.) [25] and reduces postoperative morbidity and mortality [26], [27]. However, subsequent meta-analyses showed no significant effect on mortality [28], [29]. This lack of consistent evidence combined with advances in surgical techniques and the growing adoption of less invasive methods of regional analgesia delivery has led to a decline in the use of EA. The necessity for EA in thoracoscopic surgical procedures has not been fully evaluated and a review of the literature yielded no prospective trials comparing EA vs. no EA in patients undergoing thoracoscopic procedures.

The aim of this study is to assess the shift in prevalence of the use of EA and its impact on the postoperative short-term outcomes following lobectomy by MIS or thoracotomy in 
patients with NSCLC. We analyzed two different time cohorts (early-and late-time period) to assess the dichotomous trends in the use of EA and the application of MIS.

\section{Materials and Methods}

\subsection{Study cohort}

Following approval by the institutional review board at Memorial Sloan Kettering Cancer Center (MSK), we conducted this retrospective study using clinical data obtained from the MSK Thoracic Surgery Service's prospectively maintained lung cancer database. We identified consecutive patients who had been treated with lobectomy for pathologic stage IIII primary NSCLC. The early-time period was defined by patients who underwent surgery between January 1, 2009 and December 31, 2010 while the late-time period included operations occurring between January 1, 2014 and December 31, 2015. Pathologic stage was based on the seventh edition of the American Joint Committee on Cancer Staging Manual [30]. Our exclusion criteria included: patients who underwent induction therapy; the presence of multiple nodules; a previous lung cancer diagnosis within the past two years; a prior lung resection; concurrent other malignant disease progression; and unknown status for EA (Figure 1). We also excluded patients who had an intraoperative conversion from MIS to thoracotomy in order to avoid the potential influence of intraoperative events such as bleeding on postoperative outcomes.

The option to use EA was proposed by the thoracic surgeon during the informed consent discussion; a decision was made following discussion between the patient, surgeon, and anesthesiologist. Supplemental medications for perioperative pain management did not differ by the type of surgery. These supplements included intermittent intravenous and/or transdermal patch administration of fentanyl or Dilaudid, with or without use of Toradol. Local anesthesia with lidocaine patch and intercostal nerve blocks was used according to the preference of the surgeon and anesthesiologist.

\subsection{Data collection}

Clinicopathologic data were obtained by reviewing patient medical records and included: age at surgery; sex; smoking status; history of chronic obstructive pulmonary disease (COPD); history of cardiovascular disease (CVD; which includes myocardial infarction, congestive heart failure, and peripheral vascular disease); history of diabetes mellitus (DM); body mass index (BMI); forced expiratory volume in one second (FEV1); diffusion capacity of the lung for carbon monoxide (DLCO); resected lobe; pathologic tumor size; pathologic stage (p-Stage); and histologic subtype (e.g., adenocarcinoma). All preoperative variables were evaluated within the three months leading up to surgery.

We also obtained perioperative data including type of lobectomy, surgical approach (MIS, thoracotomy, or conversion to thoracotomy from MIS), and postoperative pain management within 24 hours following surgery from operative records, anesthesia records (including post anesthesia care unit records), and nursing assessment charts. MIS included both VATS and RATS. Our definition of MIS was consistent with the consensus definition used in the Cancer and Leukemia Group B 39802 study [31]. Conversion was defined as the use of a 
rib-spreading thoracotomy at any point after initiation of MIS. The use of EA was defined as infusion lasting $\geq 24$ hours following surgery.

\subsection{Endpoints}

The endpoints of this study were length of stay, grade 2 morbidity, severe (grade $\geq 3$ ) morbidity within 30 days after surgery (grade was determined in accordance with Common Terminology Criteria for Adverse Events [CTCAE] guidelines [32]), and mortality at 30 days after surgery.

\subsection{Statistical analysis}

The association between clinical factors and time periods (2009-2010 vs. 2014-2015) and the association between clinical factors and pain management (no EA vs. EA) were evaluated using Mann-Whitney U test for continuous variables and Fisher's exact test for categorical variables. All statistical analyses were conducted using IBM SPSS Statistics 24 (IBM, United States of America). All statistical tests were two-sided and $\mathrm{p}<0.05$ was considered statistically significant.

\section{Results}

\subsection{Patient clinicopathologic characteristics}

A total of 793 patients were included in this study, with 512 patients in the MIS group (2009-2010, $\mathrm{n}=204 ; 2014-2015, \mathrm{n}=308)$ and 281 patients in the thoracotomy group (2009-2010, $\mathrm{n}=182 ; 2014-2015, \mathrm{n}=99)$. Table 1 compares the clinicopathologic factors between early- and late-time periods in the MIS and thoracotomy groups. In the MIS group, a majority $(95 \%)$ of patients in the early-time period underwent EA; however, in the latetime period, only $51 \%$ of patients underwent EA following MIS lobectomy ( $<<0.001)$. There were no differences in patient preoperative comorbidities, pulmonary function (PFTs), resected lobes, or pathologic findings. In the thoracotomy group, the late-time period was associated with a greater proportion of male patients, former smokers, higher BMIs, and higher p-Stages compared to the early-time period. There was also a statistically significant difference in the use of EA following lobectomy via thoracotomy (2009-2010 vs. $2014-2015$, $96 \%$ vs. $89 \%$; $p=0.045$ ), though this was much less pronounced than the abovementioned difference in the MIS group. (MIS: 2009-2010 vs. 2014-2015, 95\% vs. 51\%; $\mathrm{p}<0.001)$.

\subsection{Length of stay, postoperative morbidity and mortality}

Between the early- and late-time period groups, there was no statistically significant difference in length of stay, mortality, incidence of grade 2 morbidity, or severe postoperative morbidities (any morbidity, respiratory morbidity, and cardiovascular morbidity) within the MIS and thoracotomy groups (Table 1). 


\subsection{Comparison between patients with EA vs. without EA following MIS lobectomy in late- time period}

Table 2 shows a comparison of patient clinicopathologic characteristics and outcomes between patients who received EA vs. no EA following MIS lobectomy during the late-time period. There was no difference in preoperative, surgical, and pathologic factors between patients who underwent EA and those who did not. Length of stay in patients without EA was shorter than that in patients with EA (no EA vs. EA, 3 days vs. 4 days, $\mathrm{p}=0.038$ ). There was no difference in postoperative morbidity and mortality between the EA and no EA groups.

\section{Discussion}

In this study, we demonstrated a shift in prevalence of the use of MIS and EA using two different time cohorts (2009-2010 and 2014-2015). The observed decrease in the use of EA with the increasing rate of MIS lobectomy did not negatively affect short-term postoperative outcomes (length of stay, grade $\geq 2$ respiratory or cardiovascular morbidities, and 30-day mortality). The strengths of this study are as follows: 1) uniform study population with functional (BMI, comorbidities, and PFTs), and pathological data, which is helpful for assessing potential bias between groups; 2) two different time cohorts were examined to assess the dichotomous trends in the use of EA and the application of MIS; and 3) this study utilized detailed, cause-specific morbidity assessment using CTCAE grading.

The use of EA, although credited with several postoperative benefits leading to use as a standard-of-care in thoracotomy patients, can be associated with a multitude of complications, including placement-related issues such as dislodgement or "failure", as well as side effects such as hypotension and urinary retention [26, 33]. Furthermore, when compared to EA, patients who received systemic analgesia alone do not require longer hospitalizations, and in fact, require smaller opioid dosages at the time of discharge [34]. In this retrospective study setting, we did not investigate EA-related complications because of the difficulty in distinguishing between EA-related complications and non-EA-related complications (e.g., urinary retention, hypotension). However, we demonstrated a shorter length of stay in patients who did not undergo EA compared to patients who underwent EA following MIS lobectomy, which is consistent with the previous report [34].

With increasing use of MIS procedures and increasing emphasis on reduced number of inpatient procedures, stay and costs, it is important to choose appropriate modalities of postoperative pain management for thoracic patients. Although a prospective study is warranted to investigate such a modality, our study provides strong retrospective evidence that decreasing use of EA is not associated with increasing postoperative morbidity or inpatient stay. This data argues against the traditional thought process that calls for routine use of EA.

There are several limitations in this study. First, because of the retrospective nature of this study, the potential selection bias between patients who underwent EA and patients who did not, cannot be fully addressed. However, we demonstrated that there were no differences in comorbidities, PFTs, and pathologic characteristics between the EA and no EA groups. Second, we did not assess supplemental pain medications (and their resultant side effects) or 
perioperative patient care practices which might have changed between the two time periods or differed between the EA and no EA groups. Third, because of factors associated with the MIS learning curve and change of anesthesia practice, we selected two different study periods, not consecutive years. Although the study periods represent overall practice patterns, the observations are not validated in a propensity-matched series or a prospective trial. Such studies are warranted to provide definitive conclusions $[35,36]$.

\subsection{Conclusion}

As MIS becomes more commonplace for the treatment of thoracic malignancies, questioning surgical dogma, exploring innovative techniques, and redefining our "gold standards" will be paramount to the development of this rapidly expanding field. As such, our study showed that the decreased use of EA in postoperative pain management does not result in an increase in morbidity or mortality. A prospective, randomized study would be necessary to validate our findings, that it is safe to use alternative methods of acute postoperative pain management in patients undergoing MIS lobectomy for Stage I-III NSCLC.

\section{Acknowledgments:}

Funding Sources: The authors' laboratory work is supported by grants from the National Institutes of Health (P30 CA008748, R01 CA236615 and R01 CA235667), the U.S. Department of Defense (BC132124, LC160212, CA170630, and CA180889), the Emerson Collective Cancer Research Fund, the Derfner Foundation, the Joanne and John DallePezze Foundation, the Mr. William H. Goodwin and Mrs. Alice Goodwin, the Commonwealth Foundation for Cancer Research, and the Experimental Therapeutics Center of Memorial Sloan Kettering Cancer Center. None of the funding sources had any role in study design; in collection, analysis and interpretation of data; in the writing of the report; and in the decision to submit the article for publication.

\section{Abbreviations}

BMI

COPD

CVD

CTCAE

DLCO

DM

EA

FEV1

MIS

MSK

NSCLC

PFTs body mass index

chronic obstructive pulmonary disease

cardiovascular disease

Common Terminology Criteria for Adverse Events

diffusion capacity of the lung for carbon monoxide

diabetes mellitus

epidural analgesia

forced expiratory volume in one second

minimally invasive surgery

Memorial Sloan Kettering Cancer Center

non-small cell lung cancer

pulmonary function tests

Lung Cancer. Author manuscript; available in PMC 2021 January 01. 

RATS
robotic-assisted thoracic surgery
VATS
video-assisted thoracic surgery

\section{References}

1. Ceppa DP, et al. Thoracoscopic lobectomy has increasing benefit in patients with poor pulmonary function: a Society of Thoracic Surgeons Database analysis. Ann Surg, 2012 256(3): p. 487-93. [PubMed: 22868367]

2. Paul S, et al. Thoracoscopic lobectomy is associated with lower morbidity than open lobectomy: a propensity-matched analysis from the STS database. J Thorac Cardiovasc Surg, 2010 139(2): p. 366-78. [PubMed: 20106398]

3. Paul S, et al. Outcomes after lobectomy using thoracoscopy vs thoracotomy: a comparative effectiveness analysis utilizing the Nationwide Inpatient Sample database. Eur J Cardiothorac Surg, 2013 43(4): p. 813-7. [PubMed: 22826474]

4. Kent M, et al. Open, video-assisted thoracic surgery, and robotic lobectomy: review of a national database. Ann Thorac Surg, 2014 97(1): p. 236-42; discussion 242-4. [PubMed: 24090577]

5. Nomori $\mathrm{H}$, et al. What is the advantage of a thoracoscopic lobectomy over a limited thoracotomy procedure for lung cancer surgery? Ann Thorac Surg, 2001 72(3): p. 879-84. [PubMed: 11565674]

6. Park BJ, et al. Minimally invasive (robotic assisted thoracic surgery and video-assisted thoracic surgery) lobectomy for the treatment of locally advanced non-small cell lung cancer. J Thorac Dis, 2016 8(Suppl 4): p. S406-13. [PubMed: 27195138]

7. Whitson BA, et al. Video-assisted thoracoscopic surgery is more favorable than thoracotomy for resection of clinical stage I non-small cell lung cancer. Ann Thorac Surg, 2007 83(6): p. 1965-70. [PubMed: 17532379]

8. Yan TD, et al. Systematic review and meta-analysis of randomized and nonrandomized trials on safety and efficacy of video-assisted thoracic surgery lobectomy for early-stage non-small-cell lung cancer. J Clin Oncol, 2009 27(15): p. 2553-62. [PubMed: 19289625]

9. Phillips JD, et al. Factors affecting selection of operative approach and subsequent short-term outcomes after anatomic resection for lung cancer. J Am Coll Surg, 2012 215(2): p. 206-15. [PubMed: 22676962]

10. Paul S, et al. Long term survival with thoracoscopic versus open lobectomy: propensity matched comparative analysis using SEER-Medicare database. Bmj, 2014 349: p. g5575. [PubMed: 25277994]

11. Pages PB, et al. Propensity Score Analysis Comparing Videothoracoscopic Lobectomy With Thoracotomy: A French Nationwide Study. Ann Thorac Surg, 2016 101(4): p. 1370-8. [PubMed: 26872732]

12. Nwogu CE, et al. VATS lobectomy has better perioperative outcomes than open lobectomy: CALGB 31001, an ancillary analysis of CALGB 140202 (Alliance). Ann Thorac Surg, 2015 99(2): p. 399-405. [PubMed: 25499481]

13. Flores RM, et al. Lobectomy by video-assisted thoracic surgery (VATS) versus thoracotomy for lung cancer. J Thorac Cardiovasc Surg, 2009 138(1): p. 11-8. [PubMed: 19577048]

14. Falcoz PE, et al. Video-assisted thoracoscopic surgery versus open lobectomy for primary nonsmall-cell lung cancer: a propensity-matched analysis of outcome from the European Society of Thoracic Surgeon database. Eur J Cardiothorac Surg, 2016 49(2): p. 602-9. [PubMed: 25913824]

15. Boffa DJ, et al. Fewer complications result from a video-assisted approach to anatomic resection of clinical stage I lung cancer. J Thorac Cardiovasc Surg, 2014 148(2): p. 637-43. [PubMed: 24529729]

16. Yang CF, et al. Use and Outcomes of Minimally Invasive Lobectomy for Stage I Non-Small Cell Lung Cancer in the National Cancer Data Base. Ann Thorac Surg, 2016 101(3): p. 1037-42. [PubMed: 26822346]

17. Hanna WC, et al. Is video-assisted lobectomy for non-small-cell lung cancer oncologically equivalent to open lobectomy? Eur J Cardiothorac Surg, 2013 43(6): p. 1121-5. [PubMed: 23299237] 
18. Landreneau RJ, et al. Prevalence of chronic pain after pulmonary resection by thoracotomy or video-assisted thoracic surgery. J Thorac Cardiovasc Surg, 1994 107(4): p. 1079-85; discussion 1085-6. [PubMed: 8159030]

19. Bendixen M, et al. Postoperative pain and quality of life after lobectomy via video-assisted thoracoscopic surgery or anterolateral thoracotomy for early stage lung cancer: a randomised controlled trial. Lancet Oncol, 2016 17(6): p. 836-44. [PubMed: 27160473]

20. Darr C, et al. Robotic thoracic surgery results in shorter hospital stay and lower postoperative pain compared to open thoracotomy: a matched pairs analysis. Surg Endosc, 2017.

21. Agostini P, et al. Postoperative pulmonary complications following thoracic surgery: are there any modifiable risk factors? Thorax, 2010 65(9): p. 815-8. [PubMed: 20805178]

22. Sabanathan S, Eng J, and Mearns AJ, Alterations in respiratory mechanics following thoracotomy. J R Coll Surg Edinb, 1990 35(3): p. 144-50. [PubMed: 2203902]

23. Ochroch EA and Gottschalk A, Impact of acute pain and its management for thoracic surgical patients. Thorac Surg Clin, 2005 15(1): p. 105-21. [PubMed: 15707349]

24. Soto RG and Fu ES, Acute pain management for patients undergoing thoracotomy. Ann Thorac Surg, 2003 75(4): p. 1349-57. [PubMed: 12683601]

25. Ballantyne JC, et al. The comparative effects of postoperative analgesic therapies on pulmonary outcome: cumulative meta-analyses of randomized, controlled trials. Anesth Analg, 1998 86(3): p. 598-612. [PubMed: 9495424]

26. Popping DM, et al. Impact of epidural analgesia on mortality and morbidity after surgery: systematic review and meta-analysis of randomized controlled trials. Ann Surg, 2014 259(6): p. 1056-67. [PubMed: 24096762]

27. Rodgers A, et al. Reduction of postoperative mortality and morbidity with epidural or spinal anaesthesia: results from overview of randomised trials. BMJ, 2000 321(7275): p. 1493. [PubMed: 11118174]

28. Rigg JR, et al. Epidural anaesthesia and analgesia and outcome of major surgery: a randomised trial. Lancet, 2002 359(9314): p. 1276-82. [PubMed: 11965272]

29. Park WY, Thompson JS, and Lee KK, Effect of epidural anesthesia and analgesia on perioperative outcome: a randomized, controlled Veterans Affairs cooperative study. Ann Surg, 2001 234(4): p. 560-9; discussion 569-71. [PubMed: 11573049]

30. Edge SB and American Joint Committee on Cancer., AJCC cancer staging manual. 7th ed. 2010, New York: Springer xiv, $648 \mathrm{p}$.

31. Swanson SJ, et al. Video-assisted thoracic surgery lobectomy: report of CALGB 39802--a prospective, multi-institution feasibility study. J Clin Oncol, 2007 25(31): p. 4993-7. [PubMed: 17971599]

32. Common Terminology Criteria for Adverse Events (CTCAE) version 4.03. 2010; Available from: http://evs.nci.nih.gov/ftp1/CTCAE/CTCAE_4.03_2010-06-14_QuickReference_8.5x11.pdf.

33. Joshi GP, et al. A systematic review of randomized trials evaluating regional techniques for postthoracotomy analgesia. Anesth Analg, 2008 107(3): p. 1026-40. [PubMed: 18713924]

34. Kampe S, et al. The impact of epidural analgesia compared to systemic opioid-based analgesia with regard to length of hospital stay and recovery of bowel function: retrospective evaluation of 1555 patients undergoing thoracotomy. J Cardiothorac Surg, 2014 9: p. 175. [PubMed: 25417134]

35. Kosinski S, et al. Comparison of continuous epidural block and continuous paravertebral block in postoperative analgaesia after video-assisted thoracoscopic surgery lobectomy: a randomised, noninferiority trial. Anaesthesiol Intensive Ther, 2016 48(5): p. 280-287. [PubMed: 28000203]

36. Wu HL, et al. Effects of epidural analgesia on cancer recurrence and long-term mortality in patients after non-small-cell lung cancer resection: a propensity score-matched study. BMJ Open, 2019 9(5): p. e027618. 


\section{Highlights}

- $\quad$ Minimally invasive surgery (MIS) lobectomy has increased over time.

- Use of epidural analgesia (EA) has decreased, especially in MIS lobectomy.

- Decreased EA use for MIS lobectomy did not negatively affect short-term outcomes. 


$$
\begin{aligned}
& \text { Lobectomy for } p-\text { Stage } I-\text { III NSCLC }(n=1087) \\
& \qquad \begin{array}{l}
2009-10, n=525 \\
2014-15, n=562
\end{array}
\end{aligned}
$$

Excluded ( $n=294)$

- Induction therapy ( $\mathrm{n}=185)$

- Concurrent other disease progression $(n=13)$

- Conversion from MIS to thoracotomy $(n=86)$

- Unknown status for epidural anesthesia $(n=10)$

\section{Study cohort $(n=793)$}

$2009-10, n=386$

$2014-15, n=407$

$$
\begin{gathered}
\text { MIS }(n=512) \\
2009-10, n=204 \\
2014-15, n=308
\end{gathered}
$$

Thoracotomy $(\mathrm{n}=281)$

$2009-10, n=182$

$2014-15, n=99$

Figure 1.

CONSORT diagram

MIS, minimally invasive surgery; NSCLC, non-small cell lung cancer; p-Stage, pathologic stage. 


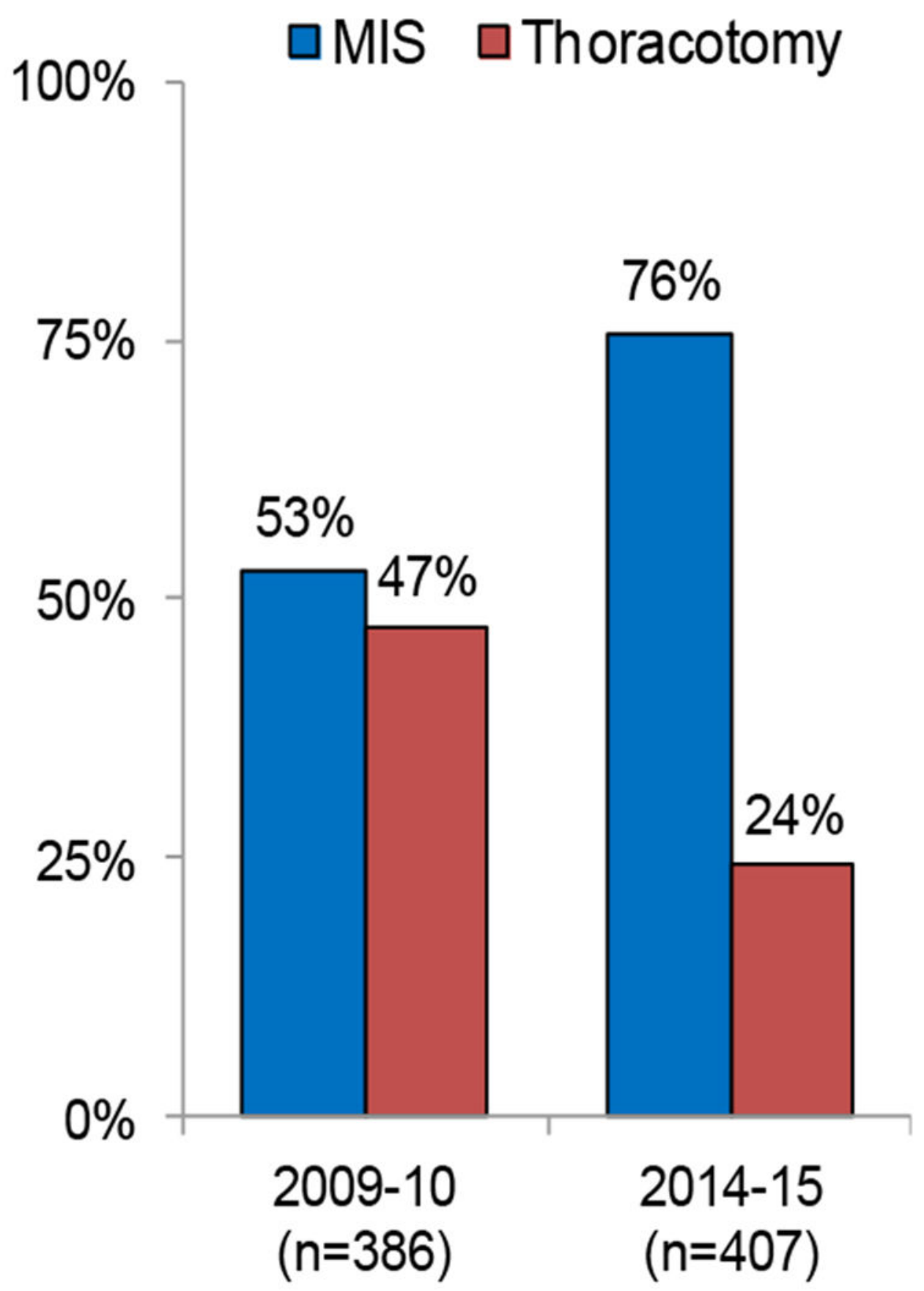

Figure 2.

Shift of prevalence in surgical approach between 2009-2010 and 2014-2015 MIS, minimally invasive surgery. 
Table 1.

Patient demographics and outcomes - comparison between early-time period (2009-2010) versus late-time period (2014-2015)

\begin{tabular}{|c|c|c|c|c|c|c|c|}
\hline & & \multicolumn{3}{|c|}{ MIS (n=512) } & \multicolumn{3}{|c|}{ Thoracotomy $(\mathrm{n}=281)$} \\
\hline & & $\begin{array}{c}2009-2010 \\
(n=204)\end{array}$ & $\underset{(n=308)}{2014-2015}$ & $\mathbf{P}$ & $\begin{array}{c}2009-2010 \\
(n=182)\end{array}$ & 2014-2015 (n=99) & $\mathbf{P}$ \\
\hline Age & & $69(61,76)$ & $69(62,75)$ & 0.5 & $69(62,77)$ & $69(63,76)$ & 0.7 \\
\hline \multirow[t]{2}{*}{ Sex } & Female & $140(69 \%)$ & $200(65 \%)$ & 0.4 & $98(54 \%)$ & $40(40 \%)$ & $\mathbf{0 . 0 3 4}$ \\
\hline & Male & $64(31 \%)$ & $108(35 \%)$ & & $84(46 \%)$ & $59(60 \%)$ & \\
\hline \multirow[t]{3}{*}{ Smoking status } & Never & $44(22 \%)$ & $64(21 \%)$ & 0.3 & $28(15 \%)$ & $15(15 \%)$ & 0.036 \\
\hline & Former & $131(64 \%)$ & $214(69 \%)$ & & $121(66 \%)$ & $77(78 \%)$ & \\
\hline & Current & $29(14 \%)$ & $30(10 \%)$ & & $33(18 \%)$ & $7(7 \%)$ & \\
\hline COPD history & & $35(17 \%)$ & $69(22 \%)$ & 0.17 & $55(30 \%)$ & $31(31 \%)$ & 0.9 \\
\hline CVD history & & $37(18 \%)$ & $54(18 \%)$ & 0.9 & $41(23 \%)$ & $30(30 \%)$ & 0.15 \\
\hline DM history & & $17(8 \%)$ & $39(13 \%)$ & 0.15 & $21(12 \%)$ & $9(9 \%)$ & 0.7 \\
\hline \multirow[t]{4}{*}{$\mathrm{CCI}$} & 0 & $109(53 \%)$ & $177(57 \%)$ & 0.11 & $74(41 \%)$ & $49(49 \%)$ & 0.4 \\
\hline & 1 & $40(20 \%)$ & $80(26 \%)$ & & $53(29 \%)$ & $24(24 \%)$ & \\
\hline & 2 & $39(19 \%)$ & $35(11 \%)$ & & $28(15 \%)$ & $15(15 \%)$ & \\
\hline & 23 & $16(8 \%)$ & $16(5 \%)$ & & $27(15 \%)$ & $11(11 \%)$ & \\
\hline BMI & & $26(23,29)$ & $26(23,30)$ & 0.4 & $26(24,30)$ & $27(25,31)$ & 0.018 \\
\hline FEV1 (\%) & & $94(82,106)$ & $97(84,108)$ & 0.2 & $88(74,101)$ & $86(73,100)$ & 0.6 \\
\hline $\operatorname{DLCO}(\%)$ & & $84(71,98)$ & $82(70,97)$ & 0.2 & $80(66,93)$ & $79(67,92)$ & 0.7 \\
\hline \multirow[t]{5}{*}{ Resected lobe } & RUL & $85(42 \%)$ & $109(35 \%)$ & 0.4 & $56(31 \%)$ & $38(38 \%)$ & 0.3 \\
\hline & RML & $9(4 \%)$ & $19(6 \%)$ & & $10(5 \%)$ & $8(8 \%)$ & \\
\hline & RLL & $34(17 \%)$ & $66(21 \%)$ & & $42(23 \%)$ & $14(14 \%)$ & \\
\hline & LUL & $50(25 \%)$ & $70(23 \%)$ & & $43(24 \%)$ & $24(24 \%)$ & \\
\hline & LLL & $26(13 \%)$ & $44(14 \%)$ & & $31(17 \%)$ & $15(15 \%)$ & \\
\hline \multirow[t]{2}{*}{ Epidural } & No & $10(5 \%)$ & $150(49 \%)$ & $<0.001$ & $8(4 \%)$ & $11(11 \%)$ & 0.045 \\
\hline & Yes & $194(95 \%)$ & $158(51 \%)$ & & $174(96 \%)$ & $88(89 \%)$ & \\
\hline $\begin{array}{l}\text { Tumor size } \\
(\mathrm{cm})\end{array}$ & & $2.0(1.5,2.5)$ & $2.1(1.5,3.0)$ & 0.2 & $2.8(2.0,4.3)$ & $3.0(2.0,5.2)$ & 0.1 \\
\hline \multirow[t]{2}{*}{ pStage } & 1 & $163(80 \%)$ & $244(79 \%)$ & 0.9 & $121(66 \%)$ & $49(49 \%)$ & 0.007 \\
\hline & 22 & $41(20 \%)$ & $64(21 \%)$ & & $61(34 \%)$ & $50(51 \%)$ & \\
\hline \multirow[t]{3}{*}{ Histology } & Adenocarcinoma & $181(89 \%)$ & $264(86 \%)$ & 0.8 & $120(66 \%)$ & $69(70 \%)$ & 0.3 \\
\hline & Squamous & $18(9 \%)$ & $33(11 \%)$ & & $43(24 \%)$ & $26(26 \%)$ & \\
\hline & Adenosquamous & $2(1 \%)$ & $3(1 \%)$ & & $4(2 \%)$ & $1(1 \%)$ & \\
\hline
\end{tabular}

Lung Cancer. Author manuscript; available in PMC 2021 January 01. 


\begin{tabular}{|c|c|c|c|c|c|c|}
\hline & \multicolumn{3}{|c|}{ MIS (n=512) } & \multicolumn{3}{|c|}{ Thoracotomy (n=281) } \\
\hline & $\begin{array}{c}2009-2010 \\
(n=204)\end{array}$ & $\begin{array}{c}2014-2015 \\
(n=308)\end{array}$ & $\mathbf{P}$ & $\begin{array}{c}2009-2010 \\
(n=182)\end{array}$ & 2014-2015 (n=99) & $\mathbf{P}$ \\
\hline Large/pleomorphic & $3(1 \%)$ & $8(3 \%)$ & & $15(8 \%)$ & $3(3 \%)$ & \\
\hline \multicolumn{7}{|l|}{ Outcomes } \\
\hline LOS & $4(3,5)$ & $3(3,5)$ & 0.3 & $5(4,7)$ & $4(3,7)$ & 0.2 \\
\hline Grade $2 *$ morbidity (any) & $20(10 \%)$ & $33(11 \%)$ & 0.8 & $27(15 \%)$ & $14(14 \%)$ & 1 \\
\hline Grade $2^{*}$ morbidity (respiratory) & $7(3 \%)$ & $19(6 \%)$ & 0.2 & $10(5 \%)$ & $9(9 \%)$ & 0.3 \\
\hline Grade $2 *$ morbidity (cardiovascular) & $13(6 \%)$ & $16(5 \%)$ & 0.6 & $15(8 \%)$ & $4(4 \%)$ & 0.2 \\
\hline Severe $^{\#}$ morbidity (any) & $13(6 \%)$ & $18(6 \%)$ & 0.9 & $22(12 \%)$ & $14(14 \%)$ & 0.7 \\
\hline Severe ${ }^{\#}$ morbidity (respiratory) & $6(3 \%)$ & $11(4 \%)$ & 0.8 & $17(9 \%)$ & $12(12 \%)$ & 0.5 \\
\hline Severe ${ }^{\#}$ morbidity (cardiovascular) & $1(0.5 \%)$ & $2(1 \%)$ & 1 & $4(2 \%)$ & $1(1 \%)$ & 0.7 \\
\hline $\begin{array}{l}\text { 30-day } \\
\text { mortality }\end{array}$ & $1(0.5 \%)$ & $2(1 \%)$ & 1 & $0(0 \%)$ & $2(2 \%)$ & 0.12 \\
\hline
\end{tabular}

Data are number $(\%)$ or median $(25 \%, 75 \%)$.

* Grade 2 determined by common terminology criteria for adverse events (CTCAE).

${ }^{\#}$ CTCAE grade $\geq 3$.

BMI, body mass index; CCI, Charlson comorbidity index; COPD, chronic obstructive pulmonary disease; CVD, cardiovascular disease; DLCO, diffusion capacity of the lungs for carbon monoxide; DM, diabetes mellitus; FEV1, forced expiratory volume in 1 second; LOS, length of stay; MIS, minimally invasive surgery; pStage, pathologic stage. 
Table 2.

Patient demographics and outcomes in patients who underwent minimally invasive surgery in late-time period (2014-15) - comparison between no epidural analgesia and epidural analgesia

\begin{tabular}{|c|c|c|c|c|}
\hline & & \multicolumn{3}{|c|}{ MIS 2014-15 (n=308) } \\
\hline & & No epidural $(n=150)$ & Epidural $(n=158)$ & $\mathbf{P}$ \\
\hline Age & & $68(62,74)$ & $70(62,76)$ & 0.077 \\
\hline \multirow[t]{2}{*}{ Sex } & Female & $94(63 \%)$ & $106(67 \%)$ & 0.5 \\
\hline & Male & $56(37 \%)$ & $52(33 \%)$ & \\
\hline \multirow[t]{3}{*}{ Smoking status } & Never & $30(20 \%)$ & $34(22 \%)$ & 0.4 \\
\hline & Former & $102(68 \%)$ & $112(71 \%)$ & \\
\hline & Current & $18(12 \%)$ & $12(8 \%)$ & \\
\hline COPD history & & $33(22 \%)$ & $36(23 \%)$ & 0.9 \\
\hline CVD history & & $29(19 \%)$ & $25(16 \%)$ & 0.5 \\
\hline DM history & & $21(14 \%)$ & $18(11 \%)$ & 0.5 \\
\hline \multirow[t]{4}{*}{$\mathrm{CCI}$} & 0 & $87(58 \%)$ & $90(57 \%)$ & 0.9 \\
\hline & 1 & $41(27 \%)$ & $39(25 \%)$ & \\
\hline & 2 & $15(10 \%)$ & $20(13 \%)$ & \\
\hline & $\geq 3$ & $7(5 \%)$ & $9(6 \%)$ & \\
\hline BMI & & $26(23,30)$ & $27(23,31)$ & 0.9 \\
\hline FEV1 $(\%)$ & & $96(84,106)$ & $98(85,110)$ & 0.5 \\
\hline $\operatorname{DLCO}(\%)$ & & $83(72,98)$ & $82(68,96)$ & 0.5 \\
\hline \multirow[t]{5}{*}{ Resected lobe } & RUL & $59(39 \%)$ & $50(32 \%)$ & 0.2 \\
\hline & RML & $10(7 \%)$ & $9(6 \%)$ & \\
\hline & RLL & $24(16 \%)$ & $42(27 \%)$ & \\
\hline & LUL & $33(22 \%)$ & $37(23 \%)$ & \\
\hline & LLL & $24(16 \%)$ & $20(13 \%)$ & \\
\hline Tumor size $(\mathrm{cm})$ & & $2.1(1.6,3.0)$ & $2.2(1.5,3.2)$ & 0.9 \\
\hline \multirow[t]{2}{*}{ pStage } & 1 & $121(81 \%)$ & $123(78 \%)$ & 0.6 \\
\hline & $\geq 2$ & $29(19 \%)$ & $35(22 \%)$ & \\
\hline \multirow[t]{4}{*}{ Histology } & Adenocarcinoma & $121(81 \%)$ & $143(91 \%)$ & 0.15 \\
\hline & Squamous & $22(15 \%)$ & $11(7 \%)$ & \\
\hline & Adenosquamous & $2(1 \%)$ & $1(1 \%)$ & \\
\hline & Large/pleomorphic & $5(3 \%)$ & $3(2 \%)$ & \\
\hline \multicolumn{5}{|l|}{ Outcomes } \\
\hline LOS & & $3(2,5)$ & $4(3,5)$ & $\mathbf{0 . 0 3 8}$ \\
\hline
\end{tabular}

Lung Cancer. Author manuscript; available in PMC 2021 January 01. 


\begin{tabular}{lccc}
\hline & \multicolumn{3}{c}{ MIS 2014-15 (n=308) } \\
\cline { 2 - 4 } & No epidural (n=150) & Epidural (n=158) & P \\
\hline Grade $2{ }^{*}$ morbidity (any) & $17(11 \%)$ & $16(10 \%)$ & 0.9 \\
Grade $2{ }^{*}$ morbidity (respiratory) & $9(6 \%)$ & $10(6 \%)$ & 1 \\
Grade $2{ }^{*}$ morbidity (cardiovascular) & $8(5 \%)$ & $8(5 \%)$ & 1 \\
\hline Severe ${ }^{\#}$ morbidity (any) & $7(5 \%)$ & $11(7 \%)$ & 0.5 \\
Severe ${ }^{*}$ morbidity (respiratory) & $6(4 \%)$ & $5(3 \%)$ & 0.8 \\
Severe ${ }^{\#}$ morbidity (cardiovascular) & $0(0 \%)$ & $2(1 \%)$ & 0.5 \\
\hline 30 -day mortality & $0(0 \%)$ & $2(1 \%)$ & 0.5 \\
\hline
\end{tabular}

Data are number $(\%)$ or median $(25 \%, 75 \%)$.

*

* Grade 2 determined by common terminology criteria for adverse events (CTCAE).

\# CTCAE grade 23 .

BMI, body mass index; CCI, Charlson comorbidity index; COPD, chronic obstructive pulmonary disease; CVD, cardiovascular disease; DLCO, diffusion capacity of th e lungs for carbon monoxide; DM, diabetes mellitus; FEV1, forced expiratory volume in 1 second; LOS, length of stay; MIS, minimally invasive surgery;pStage, pathologic stage. 